MSCRA

3,1

\section{6}

Received 13 October 2020

Revised 6 December 2020

Accepted 15 December 2020

\title{
Reverse logistics uncertainty in a courier industry: a triadic model
}

\author{
Michael Wang
}

Faculty of Engineering Technology and Science, Higher Colleges of Technology, Abu Dhabi, United Arab Emirates

Bill Wang

Business Information Systems, Auckland University of Technology, Auckland, New Zealand, and

Ricky Chan

Department of Marketing, School of Business, Auckland University of Technology, Auckland, New Zealand

\begin{abstract}
Purpose - Due to increasing supply chain complexity, the supply chain uncertainty has become an imperative issue, which hinders the development of modern logistics and supply chain management. The paper attempts to conceptualize reverse logistics uncertainty from supply chain uncertainty literature and present the types of reverse logistics uncertainty in a triadic model.

Design/methodology/approach - The concept of reverse logistics uncertainty is developed based on a triadic model of logistics uncertainty and supply chain uncertainty literature. A desk research is conducted to develop a taxonomy of reverse logistics uncertainty. To better depict the reverse logistics uncertainty, we use case studies to discuss the types of reverse logistics uncertainty in the triadic model.

Findings - The study reveals four types of supply chain uncertainties in the reverse logistics. We call them reverse logistics uncertainty. Type-A and Type-B uncertainty are new types of supply chain uncertainty in the reverse logistics.

Research limitations/implications - The types of reverse logistics uncertainty have not been empirically validated in industries. Especially, the two new types including Type-A and Type-B reverse uncertainty need further exploration.

Originality/value - Although reverse logistics has been discussed in the past decades, very few studies have been conducted on the supply chain uncertainty in returns management arena. The paper offers valuable insights to better understand the supply chain uncertainty in the reverse logistics. This also provides suggestions for both managers and researchers to reflect on the reverse logistics uncertainty management and business sustainability.
\end{abstract}

Keywords Reverse logistics uncertainty, Supply chain uncertainty, Uncertainty management,

Logistics management, Courier

Paper type Conceptual paper

\section{Introduction}

Both forward and reverse logistics (RL) link the different suppliers, manufacturers, wholesalers and retail stores in supply chains (Govindan et al., 2015). According to the American Reverse Logistics Executive Council, RL is defined as "The process of planning, implementing, and

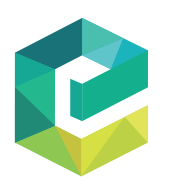

Modern Supply Chain Research and Applications Vol. 3 No. 1, 2021 pp. 56-73 Emerald Publishing Limited 2631-3871 DOI 10.1108/MSCRA-10-2020-0026
(C) Michael Wang, Bill Wang and Ricky Chan. Published in Modern Supply Chain Research and Applications. Published by Emerald Publishing Limited. This article is published under the Creative Commons Attribution (CC BY 4.0) license. Anyone may reproduce, distribute, translate and create derivative works of this article (for both commercial and non-commercial purposes), subject to full attribution to the original publication and authors. The full terms of this license may be seen at http:// creativecommons.org/licences/by/4.0/legalcode

The paper comprises some parts from the first author's unpublished thesis. The authors would like to thank the editor and the anonymous reviewers for the constructive feedback to help improve the article. 
controlling the efficient, cost effective flow of raw materials, in-process inventory, finished goods and related information from the point of consumption to the point of origin for the purpose of recapturing value or proper disposal" (Govindan et al., 2015).

An effective and efficient supply chain system needs a well-designed distribution channel and logistics network to perform its supply chain activities. The traditional logistics management often focuses on the forward logistics, which is used to control the forward movement of physical good from point of origin to the point of consumption. An RL manages the reverse flow of physical goods from the final consumers to the retailer, manufacturer or recycling (Govindan et al., 2012). Due to the increasing environmental pressure, such as climate changes, population, energy, regulations, pollution, waste reduction etc., firms require the RL to collect, reuse, recondition, remanufacture, recycle, dispose their items to reduce the waste and mitigate the negative impacts and resource shortages caused by economic activities to achieve sustainable development in a long run. RL is a primary component of green supply chain management initiative (Eltayeb et al., 2011; Govindan et al., 2015; Khor et al., 2016).

Strategic outsourcing the transportation and logistics is considered as a strategic solution to reduce the costs (Beier, 1989), especially during the global pandemic crisis, many firms attempted to minimize their costs in every possible way. Using third party logistics providers such as courier delivery is viewed as an effective way to reduce the logistics cost. Today, courier service has been widely used for RL.

Modern RL has been given new meaning in the Industry 4.0 era. Industry 4.0 was described as technologies whose main characteristics involve the integration of physical machinery and devices with network sensors and software, used to predict, control and plan for a new level of value chain organization and management across the life cycle of products (Kagermann et al., 2013). RL enables a circular supply chain and closed-loop life cycle management of products, it is now closely associated with the "sustainability", "waste reduction", "green" and "recycling" (Geissdoerfer et al., 2018; Hervani et al., 2005). This also has positive effects on environment and society (Govindan and Bouzon, 2018). As firms often use a courier service provider (CSP) to perform their returns, for example, to use courier service to collect the return products from customers. In the study, we focus on the RL in the CSP, the definition of the CSP is a logistics firm that provides a courier service to its customers of outsourced (or "third party") logistics and delivery service for part or all of their supply chain management functions.

Supply chain uncertainty is an issue in the CSPs (Wang, 2018). Although studies have discussed the supply chain uncertainty in the logistics and supply chain (Flynn et al., 2016; Simangunsong et al., 2012; Sreedevi and Saranga, 2017), very few studies have been conducted on the supply chain uncertainty in the RL. Moreover, reverses logistics is often viewed as a supportive role in green supply chain management studies (Eltayeb et al., 2011; Govindan et al., 2015). In fact, RL have much more uncertainties than the forward logistics, due to the complexity of the return procedures (Davis, 1993). There is a crucial need to improve the RL performance to support green supply chain initiatives (Eltayeb et al., 2011). In this paper, we proposed the concept of RL uncertainty based on a triadic model of logistics uncertainty. The contingency theory is adopted to further support the study. The triadic model reveals five types of the RL uncertainty in the RL operations. This would provide insights into uncertainty management in RL and sustainability.

The remainder of this paper is structured as follows. First, we introduce the courier delivery. Then, we look at RL and supply chain uncertainty from the existing literature. In the following sections, we offer a triadic model and taxonomy of RL uncertainty that allows us to classify the types of uncertainty in the RL operations. Case studies are presented based on the triadic model to help readers to better understand the types of RL uncertainties. The subsequent sections provide the conclusion and recommendation. 
MSCRA

3,1

\section{8}

\section{Courier delivery}

Typically, a courier service is started from a pickup; once a courier company received a request from a customer, the origin courier depot arranges for a courier pickup. The pickup courier usually uses a relatively small vehicle/van to collect the parcels from the shipper to the local depot. In the origin depot, the parcels are consolidated, then a larger vehicle is used to deliver the freight to the central hub. In the case that a client has a special requirement, such as a large volume of parcels movement, a trailer can often be arranged for the customer. In such situations, it is likely that the lorry / truck will take the parcels direct from the customers' site to the central hub.

Before leaving the hub, parcels are sorted into delivery regions and consolidated with other parcels destined for the same area. They are then transported from the hub to the destination courier depot. Once the parcels reach the destination depot, they are sorted ready for local distribution to their final destination. Following delivery of the parcel, a number of additional value-added services may be offered, such as obtaining a proof of delivery signature, collection of a payment.

If a parcel that has been successfully delivered requires returning to its shipper, the reverse process occurs. It is picked up by the local depot driver, labelled with a return identification number / paperwork, and then transported back to the shipper via the central hub and then the shipper's local depot. Returns are often the results of forward logistics and may be redirected into forward logistics systems after proper processing (Wang et al., 2017). There are two common types of courier delivery service including domestic and international. The following subsections depict the domestic and international courier delivery.

\subsection{Domestic courier delivery}

Please note that the activities may vary in different CSPs, the typical domestic courier delivery provides a snapshot in the New Zealand (NZ) courier industry. Generally speaking, the domestic courier service is comprised of six separate activities The set of transactions in the transportation chain are (1) a domestic pickup courier collects a parcel from a shipper (the sender of a parcel); (2) and transports the parcel to an origin depot; (3) an origin depot consolidates it for air or road transit; (4) an subcontract air or road carrier transports the parcel to a destination depot; (5) the destination depot separates or deconsolidates the parcels under different delivery addresses and (6) delivery couriers delivers the parcel to its final destination (Figure 1) (Wang, 2016).

\subsection{International courier delivery}

The international courier service has similar transportation chains. However, more activities and regulated processes may be involved (i.e. customs clearance, security screening) in an

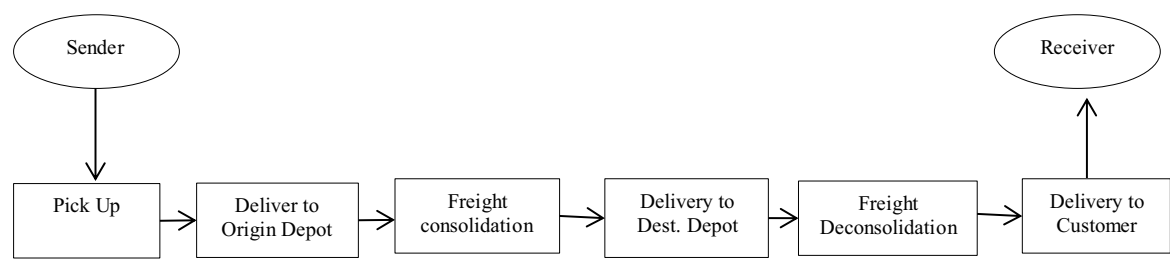

Figure 1.

The typical domestic courier delivery Wang (2016)

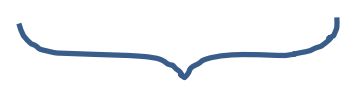

Pick up couriers

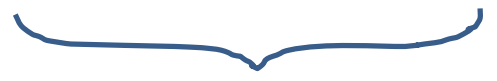

Courier Service Providers

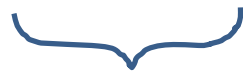

Delivery couriers 
international courier delivery. Each courier company may have different international courier partners in different countries or use own company's overseas network. Courier companies may use in-house customs brokers or freight forwarders to process customs clearance and then book the cargo with international airlines to do international air transport in most flight routes.

The international courier service is comprised of nine separate activities. The set of transactions in the transportation chain including (1) an international pickup courier collects a parcel and customs paperwork from a shipper (the sender of a parcel); (2) and transports the parcel to an origin depot; (3) an origin depot forward all the international items and paperwork to an international freight agent; (4) the international freight agent processes all the items and paperwork and consolidate the international items depend on the different destination countries; (5) an subcontract air or road carrier transports the parcel to a destination country; (6) an foreign freight forwarder organizes customs clearance and trucking service from destination airport to an foreign courier company's depot, (7) the foreign courier company's depot performs similar processes (i.e. consolidation or deconsolidation); (8) the final destination depot separates or deconsolidates the parcels under different delivery addresses and (9) a foreign delivery courier delivers the parcel to its receiver (Figure 2) (Wang, 2016).

Obviously, an international courier delivery is much more complex than a domestic delivery. There are more parties and regulated processes involved in the international transaction. And each company may have different policies and processes for international freight. Courier delivery has become a popular and effective way to move small items in

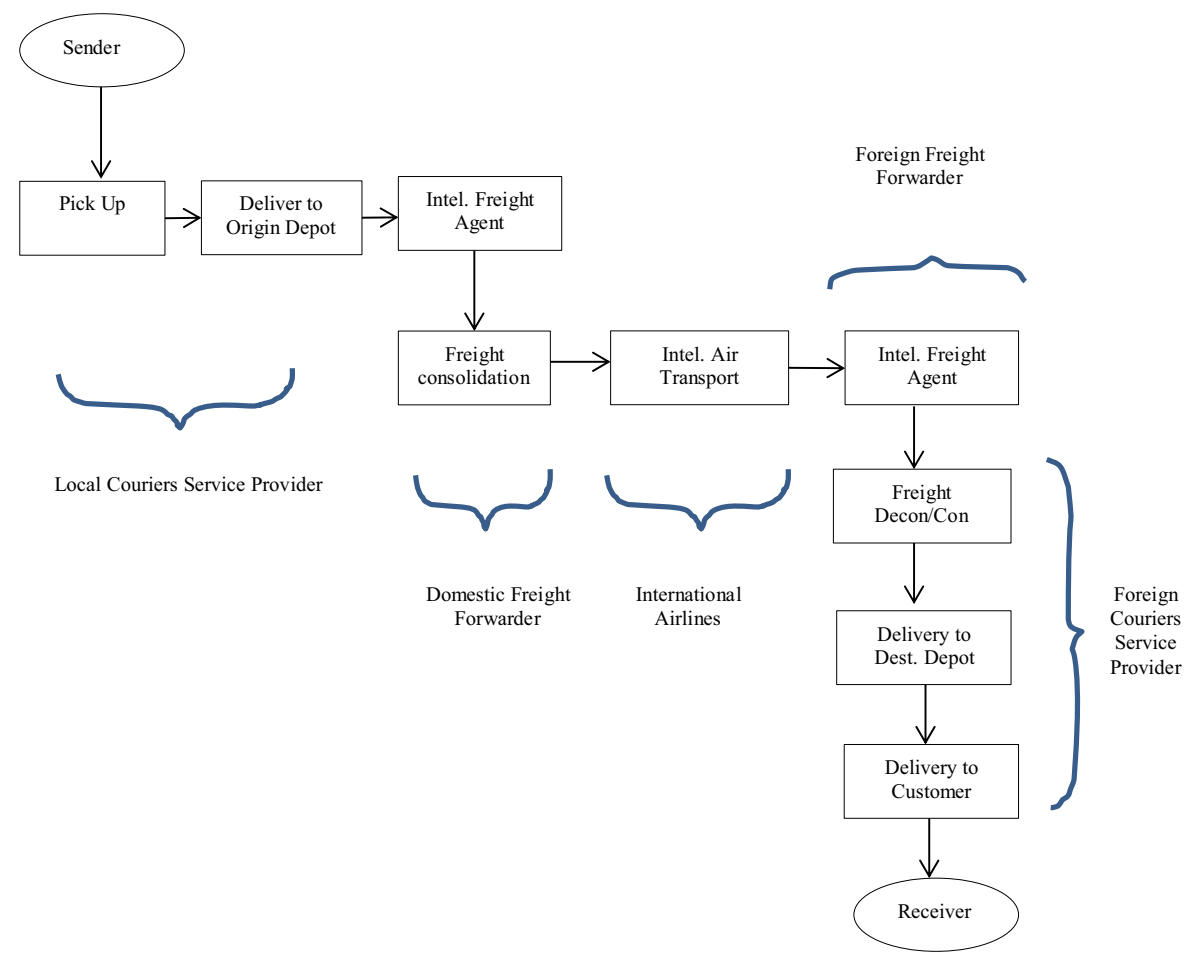

Figure 2. The typical international courier Wang (2016) 
MSCRA

3,1 today's businesses. Therefore, it is significant to know both domestic and international courier services.

\section{Theoretical background}

\subsection{Modern reverse logistics}

Modern RL is viewed as an important part of green supply chain management (GSCM) (Eltayeb et al, 2011). Although the green supply chain was later used by many scholars with various names, such as reverse supply chain, sustainable supply chains, closed-loop supply chain, circular economy (Franco, 2017), circular supply chain, the meaning of itself has not changed much. In literature, GSCM is defined as GSCM = Green Purchasing + Green Manufacturing / Materials Management + Green Distribution / Marketing + RL (Hervani et al., 2005). Green supply chain management may reduce waste, minimize pollution, save energy, conserve natural resources and reduce carbon emissions (Sundarakani et al., 2010). In this study, we study its most basic meaning RL and its uncertainty in a courier and logistics operations.

$\mathrm{RL}$ is a process to return the products and materials from the point of consumption to the forward supply chain (Amin and Zhang, 2012). The three main drivers that motivate companies to adopt RL are identified as economic, corporate citizenship and legislation (Breen and Xie, 2015) and main purposes of RL including reuse, remanufacturing and recycling (Eltayeb et al, 2011). RevLog (the European working group on RL) described the RL as "the process of planning, implementing, and controlling the efficient, cost effective flow of raw materials, in-process inventory, finished goods and related information from the point of consumption to the point of origin for the purpose of recapturing value or proper disposal". More precisely, RL is the process of moving goods from their typical final destination for the purpose of capturing value or proper disposal (Khor et al., 2016). Today, remanufacturing and refurbishing activities are included in the RL (Govindan et al., 2015). Besides, RL includes processing returned merchandise due to damage, seasonal inventory, restock, salvage, recalls and excess inventory. The return process also includes different programs, such as recycling programs, hazardous material programs, obsolete equipment disposition and asset recovery. Moreover, RL is one of the five basic categories of green supply chain initiatives (Eltayeb et al., 2011).

Rubio et al. (2008) analyse the main characteristics of articles on RL published in the production and operations management field from 1995-2005, three fundamental areas of research on RL including (1) management of the recovery and distribution of end-of-life products; (2) production planning and inventory management and (3) supply chain management issues in RL. Wang et al. (2017) provides a bibliometric analysis of RL research from 1992 to 2015, this study found that RL research started with a focus on costs and specific solutions to operational problems and has increasingly emphasized strategic issues. On the operational side, research has already demonstrated that operational RL includes multiple processes, including source reduction, product returns, reuse, recycle, disposal, repair, remanufacturing and resale. On the strategic side, researchers have moved beyond minimizing cost and improving efficiency as the sole objective of RL to study RL value, network design and RL's interfaces with other management areas.

Although many RL studies have been published in literature, very few RL researchers addressed the RL uncertainty issues. For example, Turrisi et al. (2013) studied the impact of RL on supply chain management. Hazen et al. (2014) suggest information systems play a substantial role in managing RL (RL) processes. Guo et al. (2017) studied supply chain contracts in RL. Morgan Tyler et al. (2016) found the positive moderating influence of an IT competency on the relationship between collaboration and an RL competency. Dev et al. (2020) attempts to model the RL in Industrial 4.0 technological real-time information scenarios. 
RL is now closely related to the "sustainability", "waste reduction", "green" and "Recycling" (Wang et al., 2017). RL is viewed as a part of logistics and supply chains. It is essential to understand that the operational process of RL is different from the forward logistics and involves the implementation of material disposition management rules (Govindan et al., 2012). In addition, the prime objective of $\mathrm{RL}$ is to enable the product to get its maximum value even at the end of its market life. There are various types of activities involved during the process of RL for the purpose of achieving its objective, such as packaging, repair, refurbishment, restoring, recycling, transportation and disposal. In this study, we focus on transportation in the courier industry.

\subsection{Supply chain uncertainty}

Uncertainty is complex, there are many ways to understand the uncertainty from various perspectives. First, we seek the general definition of uncertainty from Oxford English Dictionary; it is the quality of being uncertain in respect of duration, continuance, occurrence, etc.; liability to chance or accident. Also, the quality of being indeterminate as to magnitude or value; the amount of variation in a numerical result that is consistent with observation. The other definition of uncertainty under economics is a business risk which cannot be measured and whose outcome cannot be predicted or insured against. This study focuses on the RL uncertainty, which is a type of supply chain uncertainty.

Knight (1921) illustrated that the uncertainty is immeasurable. Miller (1992) argue about the uncertainty refer to the unpredictability of environmental or organizational variables that impact business performance or the insufficient information about these variables. Logistics uncertainty may occur when decision makers cannot estimate the outcome of an event or the probability of its occurrence (Sanchez-Rodrigues et al., 2008). People can use the best forecasts and do every possible analysis, but there is always uncertainty about future events. It is this uncertainty that brings risks (Waters, 2011). There is a very close relationship between risk and uncertainty, because uncertainty increase the possibility of risk occurrence, and risk is a consequence of uncertainty. In other words, risk occurs because of uncertainty about the future, this uncertainty means that unexpected events may occur, and when these unexpected events occur, they cause some kind of damage. Although uncertainty and risk often are interchangeable (Wang et al., 2015), in this study, we deliberately focus on the uncertainty in logistics and supply chain. One of the main reasons is that the triadic model is designed for RL uncertainty.

Davis (1993) establishes an uncertainty cycle and states that the supply chain uncertainty is caused by the supply chain complexity and uncertainty propagates through a manufacturing network. Three distinct sources of uncertainty including suppliers, manufacturing and customers have been revealed in this study. Mason-Jones and Towill (1998) presents a simple generic supply chain uncertainty model, including types of uncertainty from demand side, supply side, manufacturing process and control systems. Wilding (1998) develops a supply chain complexity triangle, which adds a new type of uncertainty-parallel interaction which is the situation where there is interaction between different channels of the supply chain in the sametier. This may demonstrate that interactions between parties in supply chain is a type of uncertainty. Later, researchers look at the supply chain uncertainty from the macro and micro levels and causes of the uncertainty. Such as Prater (2005) suggests that supply chain uncertainty can be divided into two levels; macro level uncertainty refer to risks due to disruptions and macro level uncertainty is a higher level category of uncertainty, whereas micro level uncertainty relates to a more specific source of uncertainty, studies the main causes of contingent uncertainty in transport operations, identifies the three types of supply chain uncertainty including customer side, company side and environment in the Australian courier industry.

Supply chain uncertainty has both positive and negative impacts on the forward logistics performance (Wang, 2018). In this paper, we predominantly focus on these negative impacts 
MSCRA

3,1

62

because these uncertainties could cause problems and inefficiency in supply chains (Davis, 1993). We live in an uncertain world, it is difficult to eliminate all uncertainties. Coronavirus disease 2019 (COVID-19) demonstrates a perfect example of supply chain environmental uncertainty. Having said that, it is important to mitigate the negative impacts of supply chain uncertainty in RL. To manage these supply chain uncertainties, the first predominant task is to identify and understand the types of supply chain uncertainty in the RL. Therefore, we proposed a triadic model of RL uncertainty based on the logistics triad (Beier, 1989) and a simple courier RL process consisting of three parties. The following section will introduce the new triadic model.

\section{A triadic model of RL uncertainty}

The first logistics triad consisting of shipper (consignor), carrier and receiver (consignee) was established by Beier (1989). Later, Larson and Gammelgaard (2001) defined a logistics triad as a cooperative, three-way relationship among a buyer of goods, the supplier of those goods and an CSP moving and/or shoring the goods between buyer and supplier used the logistics triad to develop five uncertainty sources that can have negative impacts on transport operations. In this study, a triadic model of RL uncertainty is drawn based on an extensive literature review and practical RL operations in a courier industry.

This study provides a different view on the RL uncertainty. Modern supply chain is better equipped, most sources of uncertainty can be managed by various new technologies. This study attempts to identify the types of RL uncertainty based on the interactions among three major parties including courier services provider, consignor/ return customer and consignee / return receiver. The four types of uncertainties in the triadic model are depicted in a RL transaction.

In the triadic model, the CSPs' focus is to deliver products or materials back from customers to a forward supply chain. In a forward logistics, firms focus on the cycle time, delivery time and lead time. However, form the RL operation's perspective, the customers play a vital role in the RL delivery, as a parcel return processing starts from a pickup, the customer need to collaborate and work with CSP to complete the return pickup, but the individual customers are often unable to control the pickup time. Previous study indicates that high percentage failure rate was caused by incorrect pickup (Wang et al., 2015). Another example, if people missed the rubbish collection time, the rubbish would not be collected until next time. Customer is one of the important sources of uncertainty, which could directly lead to the service failure in a RL operation. In addition, both consignor and consignee are important in the RL. Thus, we keep the consignor and consignee in the triadic model. Figure 3 shows a triadic model of RL uncertainty in this study.

The supply chain uncertainties in the RLare various due to the complexity of RL in real-world operations and many unknown factors or risks. It is impossible to capture every single uncertainty in the RL, as each return may have different elements and requirements, which may occur more uncertainties. However, serial interactions in RL occur between each party in the supply chain, i.e. a return customer and a CSP. We focus on the interactions among the firms and customers in the RL, the supply chain uncertaintiesarecategorizedasfour types. Twobrand new types of supply chain uncertainties have been established based on a well-known study Wilding (1998). Both Type-A and Type-B uncertainties are derived from the interactions between different parties; more specifically, Type-A uncertainty is derived from the interactions between CSP and its customers including both consigner and consignee in this study because both parties involve in a delivery and return. Therefore, the Type-A uncertainty is applied for both parties; Type-B uncertainty is derived from the interactions only between consigner and consignee.

The triadic model maps a simple and basic RL process and offers directions to identify the different types of uncertainty in the RL. We indicate three types of flows including psychical goods flow, information flow and financial flow in the model. In this paper, we did not 

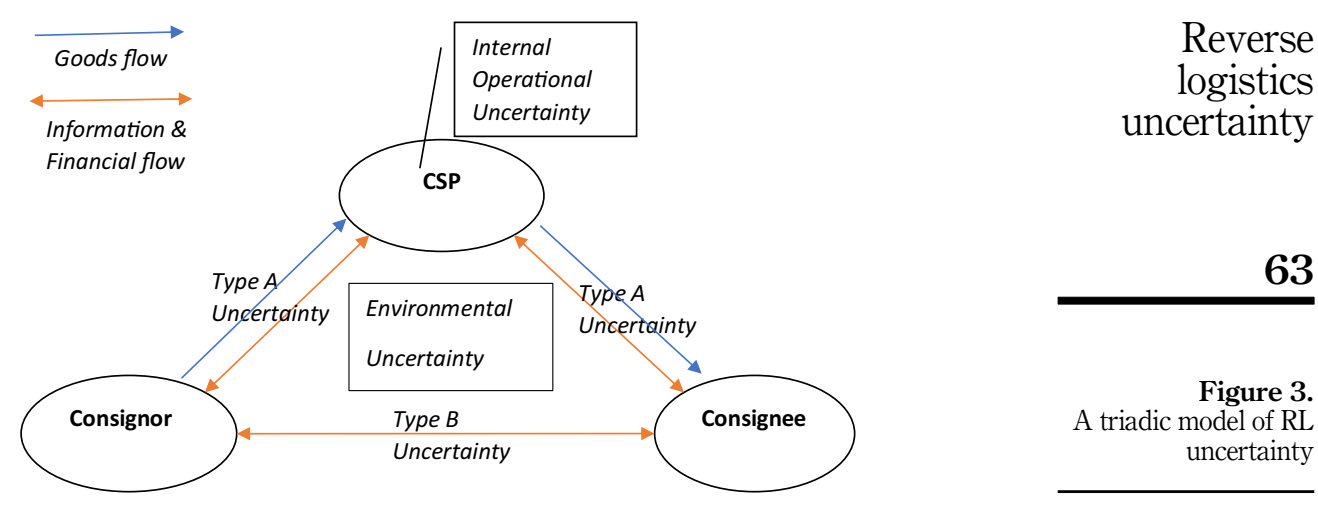

Figure 3.

A triadic model of RL uncertainty

differentiate information and financial flow, the psychical goods flow is only considered between CSP and consignor or consignee in this basic model. This helps both researchers and practitioners to better understand the supply chain uncertainties in the RL.

(1) Internal operational uncertainty refers to the RL uncertainty predominantly occurs within logistics firms during the reveres logistics delivery. For example, health and safety at work, the failure in daily operations, missing freight, damages, transport delay, etc. (Davis, 1993; Simangunsong et al., 2012; Wang et al., 2014)

(2) Type-A uncertainty refers to the RL uncertainty predominantly occurs between CSP and customers including consigner or consignee, the interactions consisting of physical goods, information and financial flows. This type A uncertainty may directly influence customer satisfaction.

(3) Type-B uncertainty refers to the RL uncertainty predominantly occurs between the consigner and consignee; the interactions mainly consisting of information and financial flows. CSP is not directly involved in this Type-B uncertainty. For example, communications, payment and goods refund between consigner and consignee.

(4) Environmental uncertainty refers to the RL uncertainty predominantly occurs in the external environment. For example, COVID-19 pandemic, China-US trade war, natural disasters, policy, fuel price, etc. (Sanchez-Rodrigues et al., 2009; Wang, 2018).

These four types of uncertainties may cover all major uncertainties in the RL services. The internal operational uncertainty typically originates from the CSPs. This type of uncertainty is considered as a control uncertainty (Davis, 1993). Type-A and Type-B are two new types of uncertainty are developed based on the study Wilding (1998), both types of uncertainties predominantly occur during the situation where there are interactions between different stakeholders in the triadic model. This study describes interactions that occur between different stakeholders including CSP and customers in the same RL channel. More specifically, Type-A uncertainty describes the relevant supply chain uncertainties between the CSP and its customers, this may include the situation where there are multiple CSPs in the same RL transaction. Type-B uncertainty describes the relevant uncertainties between the consigner and consignee, this may include the situation where there are multiple customers $(>2)$ in the same RL transaction. Sometimes, if multiple customers and CSPs have been involved in the same RL process, Type-A and B uncertainty can still be applied into the cases. The environmental uncertainty has been often mentioned in previous studies (Wang, 2016; Wang and Jie, 2019). It is from external uncertain environment. A taxonomy for supply chain uncertainties in a RL service is presented as follows. 
MSCRA

3,1

64

\section{Taxonomy of RL uncertainty}

Up to now, according to the published papers from Scopus database, which providing the most comprehensive coverage (Rovira et al., 2019), there are very few studies conducted on RL uncertainty, which are crucial to the success of the green supply chain initiatives, as $\mathrm{RL}$ is one of the five basic categories, they are eco-design, green purchasing, supplier environmental collaboration, customer environmental collaboration and RL (Eltayeb et al., 2011). This section presents a taxonomy for supply chain uncertainty in a RL (see Figure 4). There are four types of RL uncertainty including internal operational uncertainty, Type-A uncertainty, Type-B uncertainty and environment uncertainty in the triadic model. The impacts of RL uncertainty are briefly discussed at end of this section.

\subsection{Internal operational uncertainty}

The internal operational uncertainty has been widely discussed in the previous studies (Davis, 1993; Sanchez-Rodrigues et al., 2010). This type of RL uncertainty occurs in the internal operations within CSPs. For example, the advanced equipment and new technologies have been widely used in the logistics and the transport industry during the Industry 4.0 era, this may directly improve the logistics performance. However, the equipment failure and incorrect using could lead to uncertainties, which may cause potential issues. Many internal uncertainties cannot be eliminated, but the negative effects of these internal uncertainties may be reduced and minimized (Davis, 1993). This type of uncertainty inherent in the company operations, and each logistics company may have its own internal uncertainties, as each one has different logistics capability, return procedures, equipment, delivery network, personnel and company's structure and policy (Wang, 2016).

\subsection{Type-A uncertainty}

Type-A uncertainty is a new type of supply chain uncertainty. This type of uncertainty may include all the uncertainties between CSP and customers who are either business customers or individual customers. Individual customers may have a higher level of Type-A uncertainty than business customers from a CSP's point of view, due to the customers' characteristics, and often there is a long-term business relationship between CSP and business customers rather than the personal customer. We consider that Type-A is the most important type of uncertainty in the RL. Some examples of the Type-A uncertainty are delays due to customers' mistake, lack of communication between CSP and customers, insufficient capability to meet customers' requirements, etc. Many customer-related factors may easily turn into a Type-A uncertainty. There are several important factors in the Type-A uncertainty being listed as below.

5.2.1 Volume of return. The volume of return could directly influence the performance of the return processing and the charging for the different volume of return is different, as many CSPs have separated freight processing for the bulk delivery and small parcels delivery.

Figure 4.

Taxonomy of RL uncertainty in this study

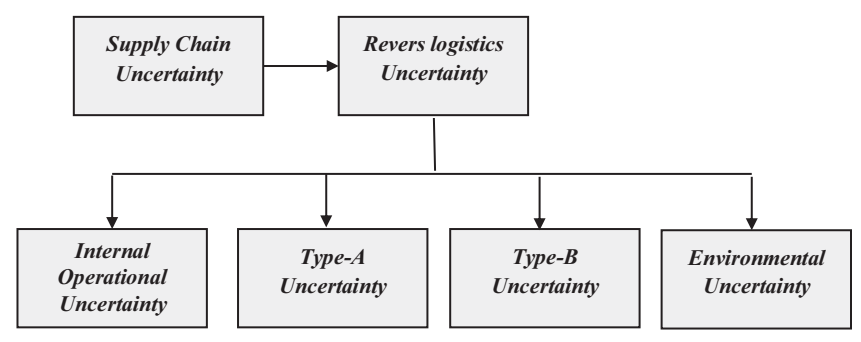


The returns need to be processed by correct return procedures to avoid any unnecessary delay and failure. Service providers may pay more attention to the individual customers.

5.2.2 Error and mistake from customer. Error and mistake from customers may directly lead to the failure, for instance, the delivery or pickup address is not clear or incorrect, the return item has not been packed correctly and the relevant return paperwork has not been completed such as custom declaration form, dangerous good declaration form, return form, etc.

5.2.3 Return frequency. Return frequency means how often a customer returns the items. Return frequency is one of the crucial dimensions in RL. The CSPs need appropriate strategies for different customers to minimize the costs and improve the performance of services. This uncertainty could be reduced and eliminated depending on the situations, for instance, a business customer such as a retailer has higher return frequency than an individual customer, and the CSP may offer regular pickup service and dedicated return services for the business customer to reduce the uncertainty.

\subsection{Type-B uncertainty}

Type-Buncertainty refers to the supply chain uncertainties between consigner and consignee. As discussed before, Type-B uncertainty is considered as a type of uncertainty, which is derived from the interactions between consigner and consignee, they may directly influence the performance of returns. RL is much more complex than a forward logistics, in the RL, often all parties including consigner, consignee and CSP are involved prior to a RL start. Although this Type-Buncertainty often does not directly involve the physical goods movement, it can influence internal operational uncertainty and Type-A uncertainty. For example, poor communication between consigner and consignee, insufficient pickup address, and unpaid delivery cost, etc. And most Type-B uncertainties are related to the information and financial flows.

\subsection{Environmental uncertainty}

Environmental uncertainty is one of the most common types of supply chain uncertainty in the forward logistics studies (Mason-Jones and Towill, 1998; Sanchez-Rodrigues et al., 2009; Wang, 2018). This type of uncertainty often occurs in the external environment and indirectly influences the internal logistics operations. In addition, environmental uncertainty can influence other types of supply chain uncertainties including Type-A and Type-B uncertainties. COVID19 pandemic is an example of environment uncertainty, it can cause various supply chain uncertainties and has direct or indirect impacts across the supply chains including RL. Other important environmental uncertainty may include technologies, market competition, economic environment, consumer behaviour, government and regulations, etc. (Wang, 2011; Wang and Jie, 2019). Some significant trends may become the external uncertainties of return, which influence the RL activities. The trends include globalization, offshoring, customization and Industry 4.0. Figure 2 illustrates the taxonomy of RL uncertainty. The following subsection discusses the impacts of supply chain uncertainties and provides some resolutions and suggestions for managing the supply chain uncertainties in the Industry 4.0 era.

\subsection{Impacts of RL uncertainty}

The impacts of RL uncertainties are significant. Typically, the impacts of logistics uncertainty on sustainable transport operations are negative (Sanchez-Rodrigues et al., 2009). The uncertainties may directly influence many aspects in firms and supply chains. For example, increasing the lead time-lead time is always predominant in logistics and supply chain activities, and many RL uncertainties are directly related to the lead time, such as unexpected delays, customer complaints, extra storage costs, etc. Therefore, it is significant to minimize and even eliminate the uncertainties in an RL system. 
MSCRA

3,1

66

Cost is an essential key performance indicator (KPI) in firms. RL uncertainties may increase the cost significantly, for instance in a courier delivery, a negative pickup job, which means an incorrect pickup job, is normally caused by the Type-A uncertainty between CSP and consignor such as wrong item, insufficient pickup address and poor communication. The negative pickup job increases both the delivery time and the cost, as couriers have to repickup it. Besides, various extra costs could be further caused by various uncertainties such as overtime costs, extra operation cost, etc.

Uncertainty may break the supply chain relationships among the parties in a RL, and this phenomenon normally is resulted from the Type-A and Type-B uncertainties such as vague requirements of return, payments, insufficient information sharing, etc. Besides, the internal operational uncertainty may influence the inter-organizational relationships.

\section{Case study}

We have described a triadic model for identifying and assessing supply chain uncertainty and its impacts from a RL operation perspective in the preceding pages. Some practitioners may question so what? Next, we will describe a few cases of the successful example of adopting different ways to reduce the types of RL uncertainty based on the model. This may shed light on RL uncertainty management. The first is about the parcel tracking system in NZ Couriers. The case shows that the technologies may be used to help reduce the types of RL uncertainty in our triadic model. The second case descries the situation how Apple manages its returns in NZ. This demonstrates that a good return process design can also help reduce the supply chain uncertainties in the model. In the final case, we will present some results that clearly indicate the types RL uncertainty in the triadic model.

\subsection{New Zealand couriers}

Information sharing is predominant in logistics and supply chain. As discussed previously, green supply chain, circular supply chain or closed-loop supply chain encompasses both forward logistics and RL. The RL information sharing ensure complete supply chain information sharing (Hayrutdinov et al., 2020; Lee et al., 2018). New Zealand Couriers (NZC) is a leading provider of network courier services to NZ businesses. NZC has successfully implemented the technologies into their delivery service to track and trace the parcels. There are emerging technologies in Industry 4.0, such as big data, artificial intelligence (AI), Internet of things (IoT), and they can help courier firms to further improve the RL system design (Dev et al., 2020). The barcode technology is used as a successful example of RL information sharing, as it often can be found in an integrated courier tracking system. The barcode technology has been well-used to record delivery information and status in NZC. The barcode's information is difficult to be modified or changed during a courier delivery process and this would result in fewer mistakes or errors and in turn lead to lower uncertainty of a return logistics process. This would help reduce the internal operational uncertainty and Type-A uncertainty. In addition, each consignment ticket barcode is a unique identification of the parcel during the courier delivery process. This allows different parties to share the parcel delivery information that has been digitalized in a real-time system. As the RL information sharing is an important part of the product life cycle information sharing, which increases the profit of the whole chain and decreases with the increase of customer's price sensitivity coefficient (Hayrutdinov et al., 2020). Every time the barcode is scanned by different parties such as pickup couriers, depot staff, truck drivers, delivery couriers during the delivery process, the RL information is recorded and uploaded to online database. Different stakeholders also can use the information for different purposes, such as the delivery verification, financial report, returns management etc. Thus, a wealth of information generated by the tracking system would help reduce the Type-A 
uncertainty and Type-B uncertainty in the model. The firm may use big data analytics to create value for customers and support decision-making (Govindan and Bouzon, 2018). Moreover, the RL information sharing maximizes the value of information across the supply chains, it improves predictability and allows different stakeholders to collaborate and share the delivery information during a return delivery. This also helps the stakeholders to against the environmental uncertainty.

\section{Reverse logistics uncertainty}

6.2 Apple return process

Apple Inc. is an American multinational corporation that designs and markets electronics such as computer software, mobile phone, personal computers, etc. The company's bestknown hardware products include the Macintosh line of computers, the iPod, the iPhone and the iPad. Apple establishes a well-rounded reverse supply chain to develop a sustainability strategy. Apple's reverse supply chain strategy focuses on collaborating closely with third party logistics (3PL) companies (Kumar et al., 2012). There are no official Apple Stores in NZ. Apple uses third party courier companies to distribute its products from its warehouse directly to the NZ customers and so is the RL. In this Apple return case, a customer contacts Apple online store customer services team to request a product return such as exchange, refund, damaged and wrong order in NZ. Once Apple Store receives the return enquiry, it will be processed case by case. Apple may refuse or accept the return request. The rejected return enquiry will be ended without further logistics process. If the return has been authorized, the customer will be informed and receive a pre-printed delivery consignment note with the detail information including return address, pick up address and contact person. The customer follows the instructions to print and attach the label on the return items. The courier dispatch team then arranges a courier pick up for the return. After return items reach the TNT depot, the forward logistics process will be performed for the return delivery. If some issues occur, for example incorrect pickup address, the courier customer service team will contact Apple to get an updated information. Then a new courier job will be generated to pick up the item. The Apple return process simplifies the information flow and operations among the parties during the return processing. Childerhouse and Towill (2003) emphasized that the simplified supply chain flow facilitated supply chain integrations, reduced the supply chain uncertainty and suggested that firms can improve their ability to handle returns through supply chain collaboration. Overall, the well-deigned, standardized and simplified return process with supply chain integration and collaboration can help reduce all types of the RL uncertainty in the Apple case.

\subsection{Interpreting findings}

We develop RL in the triadic model including CSP, consignee and consignor to demonstrate an underlying mechanism for RL uncertainty from RL perspective. The supply chain uncertainty predominantly occurs during the interactions (Wilding, 1998). Consequently, four types of RL uncertainty including internal operational, Type-A, Type-B, environmental are emerged. RL uncertainty is derived from supply chain uncertainty. Although supply chain uncertainty is unpredictable and immeasurable (Wang, 2018), some RL uncertainties can be managed or reduced through several ways in this model, we used the first case to show that the technology may be an effective way to reduce the uncertainty in a courier delivery, which is a popular delivery method for goods return. The second case is Apple return process in NZ, which may demonstrate that a good business process design help reduce the supply chain uncertainties in the model, such as simplification, standardization, gate keeping.

Many firms' return process is similar to the Apple returns in NZ. Another example, OfficeMax officemax.co.nz, which is a large American office supplies retailer for office supplies, solutions and services as well as workplace products and furniture. Its supply chain 
MSCRA

3,1

\section{8}

focuses on cross-functional alignment and supply chain efficiencies (Slone et al., 2007). OfficeMax recently closed its 14 shops across NZ and shift operations online. It uses a centralised RL system to handle all its returns from both individual and business customers in NZ. Based on the triadic model, one of the significant facets could be found from these return cases is that the consignor no longer requires to arrange a return delivery with CSP, consignor only needs to contact the consignee to book the delivery instead of CSP. The consignee works with the CSP to arrange the returns. This has significant impacts on Type-A and Type-B uncertainties, as the CSPs only have to deal with one party which is consignee, instead of dealing with both parties-consignee and consigner simultaneously. However, this requires consignee to pay more attention on the Type-B uncertainty in the RL.

Another significant facet is that the CSP plays a central role to manage the entire return process in the modern RL. Such as Apple and OfficeMax use CSPs to perform RL operations in NZ, and both has a centralised RL system, which enable consignee to maintain a good gatekeeping. This is used to filter the defective and unauthored return items and products at the entry point into the return/RL channel (Govindan et al., 2015; Guo et al., 2017). This also promotes both internal and external supply chain integrations and collaboration between firms and CSP to achieve a green/circular supply chain (Kumar et al., 2012; Slone et al., 2007). The Type-A uncertainty between CSPs and consignor may be minimized and transferred to Type-A uncertainty between CSPs and consignee and Type-B uncertainty between consignor and consignee.

Further, the triangle relationship of RL may reveal that the customer service plays a vital role to help reduce RL uncertainty, the results are in line with previous supply chain uncertainty studies in forward logistics (Amin and Zhang, 2012; Hayrutdinov et al., 2020; Sanchez-Rodrigues et al., 2008). As Type-A uncertainty between CSPs and consignor can be managed by consignee in a centralized logistics system by adopting a well-designed return system, i.e. Apple (Kumar et al., 2012), supply chain contract and a long-term supplier-buyer relationship between CSPs and consignee (Guo et al., 2017) also can overcome the Type-A uncertainty. The Type-B uncertainty trends to predominate the RL uncertainty in the model, customer is a major source of uncertainty (Wilding, 1998). The customer demand in almost every industrial sector seems to be more volatile than was the case in the past, and the supply chain uncertainty has many significant impacts on the customers (Christopher and Lee, 2004). The customer-side uncertainty is a major part of supply chain uncertainty and risk in a forward logistics (Wang, 2018). In the case study, OfficeMax offers dedicated account managers to serve its customers and solve problems, and its cross-functional alignment can better support customer in RL. Therefore, we suggest that superior customer service is key to manage the Type-B uncertainty.

\section{Conclusion and recommendation}

In this conceptual paper, according to the contingency theory, we investigate the supply chain uncertainty in a RL, which is different from a traditional logistics (Richey et al., 2005). $\mathrm{RL}$ is not a new industrial practice. However, it has received increased attention and been given new meaning including the "green", "circular", "waste reduction", "sustainability" in the modern supply chains (Franco, 2017; Khor et al., 2016). As more firms emphasized the environmental aspects in their supply chain management, environmental consideration has become one of the most important drivers in the development of RL (Eltayeb et al., 2011; Kumar et al., 2012).

This study identified four types of RL uncertainties in the triadic model, they are internal operational uncertainty, Type-A uncertainty, Type-B uncertainty and environmental uncertainty. Several case studies have been used to demonstrate the types of RL uncertainty in NZ context. In literature, RL comprise various activities (Govindan et al., 2015). We focus 
on the RL transportation in a courier industry due to the essence of the study and popularity of courier service in the modern RL.

\subsection{Research implications}

This study provides both theoretical and managerial implications and significantly contributes to the research stream of RL uncertainty. RL includes a wide range of activities across supply chain, as there are no standardized return procedures in industries. In addition, the consignee and consignor are often from the different firms, thus this makes the return situations even more complex. Therefore, we focus on the courier transportation based on the model, Type-B uncertainty may influence the Type-A uncertainty. For example, the return volume among logistics company, consigner and consignee is a critical uncertainty, which is concerned by CSPs. The volume of return also influences the economies of scales, i.e. the costs of transportation of full container load (FCL) is much cheaper than that of less than container load (LCL). Thus, we suggest that CSP should understand the return procedures between the consignee and consigner and offer routine RL design / service to better help mitigate the Type-B uncertainty, as Type-B uncertainty is closely associated with other RL uncertainties in the model.

Due to the modern supply chain complexity, the RL requires an integrated information system to link the different parties in a return procedure (Hazen et al., 2014). Information system is one of the important elements in logistics and supply chain (Hervani et al., 2005; Wang et al., 2021). It helps information sharing across entire supply chain. In our case study, NZC applied technologies to facilitate the delivery information for different parties in a RL delivery. Further, information system enables RL information sharing in supply chains, and many studies discussed the impacts of information sharing in the forward logistics management, one of famous simulations is the MIT Beer Game. The information sharing may reduce supply chain uncertainties (Wang et al., 2015). Moreover, information sharing and transparency may improve the supply chain relationships between CSPs and customers, the benefits of which are beyond we can imagine. In the Industry 4.0 era, emerging technologies such as IoT, blockchain, AI, big data, etc. may offer many new opportunities and ideas to deal with these types of supply chain uncertainty in the RL. Future study may investigate the particular technology and its implications on RL uncertainty.

There are various return activities in the return procedures. Many firms do not only receive the return items, but also, they manage the returns (Govindan et al., 2015; Kumar et al., 2012). This require supply chain collaboration and integration in RL (Morgan Tyler et al., 2016). In the case study, we reviewed the Apple return process, the return items may be remanufactured and refurbished in manufacturers, this may include recall products, outdated products, etc. while some return items have to be disposed such as un-reusable materials, battery, etc. (Kumar et al., 2012). A centralized logistics system has been proved as an effective and efficient supply chain system in previous studies (Christopher, 2005; Slone et al., 2007). The RL system could maximize the efficiency of entire system and reduce the various costs such as operations costs, inventory costs, etc. in order to improve the performance in a system wide (Dev et al., 2020). The centralized RL system can be widely employed in the RL services. Therefore, this may offer resolutions for firms to achieve the economies of scale and reduce uncertainty in the RL.

Other types of RL uncertainty including internal operations uncertainty and environmental uncertainty are important facets in the RL triadic model (Sanchez-Rodrigues et al., 2009). Although they have been well-discussed in forward logistics and supply chain studies, very few studies have been conducted to analyse these types of supply chain uncertainty in RL operation. The trends of environmental factors directly influence the RL. Such as landfill costs have increased steadily over recent years and are expected to continue to rise; products can no longer be land-filled because of environmental regulations; economic and environmental 
MSCRA

3,1

70

considerations are forcing firms to use more reusable packaging, totes and other materials; producers are required to be recycled at the end of their lifetime (Khor et al., 2016).

As all parties are required to work together to perform a return from the point of consumption to the point of origin, the supply chain relationship management is important in RL management. There are many different types of relationships in supply chains, such as alliance, outsourcing, contract, casual, etc. (Guo et al., 2017). However, stable and good supplier-buyer relationships and supply chain collaboration benefit all parties and may help to overcome some uncertain factors and optimize the return performance in the long run. To simplify the RL flow, the CSP is able to offer appropriate value-added services for customers. The characteristics of returns include a wide range of factors; some of which have been discussed in this study. Some solutions may be used to reduce this uncertainty, i.e. pre-arrange the delivery, routine services, centralized RL system and new Industry 4.0 technologies. These may shed light to manage the RL uncertainty in the modern supply chains.

\subsection{Research limitations and future researches}

This study includes several research limitations, the types of RL uncertainty are developed based on a logistics triad model and previous supply chain uncertainty studies. Because there is very limited number of published RL uncertainty studies. We used a desk research technique and descriptive analysis to understand the RL in the case study, this may limit the completeness of the results, we may not observe all the phenomena. As this is the first attempt to investigate the RL uncertainty, we only focus on a courier RL transportation in order to generalize more in-depth RL uncertainty results based on current available data and researches. The types of RL uncertainty have not been empirically validated in industries. Especially, the two new types including Type-A and Type-B uncertainties need further exploration, for example, more in-depth explanations on the hypothesized relationships among the uncertainties are required. But these research limitations offer plentiful future research directions to further examine the RL uncertainties from various angles, as there is a lack of relevant research in RL uncertainties.

Moreover, the logistics triadic model of RL uncertainty is first time published in the paper, we suggest that the triadic model needs further development from different perspectives to cope complex scenarios and represent complexity of modern logistics and supply chains. Researchers may merge the logistics triadic model with circular supply chain or intertwined supply chain to support the latest trends in logistics and supply chain management researches. More further researches may be conducted to understand the types of RL uncertainty and their interdependent relationships in a circular supply chain. Managers often have to consider the entire supply chain design and optimization. It is predominant to investigate factors which may hinder development of RL from different perspectives for different purposes across supply chains. This article contributes to the modern RL and supply chain management literature. Further researches may be conducted to distinguish the internal operational uncertainty and environmental uncertainty in forward and RL operations. This would provide further support to managers to continue improving the RL operations in a green or circular supply chain.

\section{References}

Amin, S.H. and Zhang, G. (2012), "A three-stage model for closed-loop supply chain configuration under uncertainty”, International Journal of Production Research, Vol. 51 No. 5, pp. 1-21, doi: 10. 1080/00207543.2012.693643.

Beier, F.J. (1989), “Transportation contracts and the experience effect: a framework for future research [article]", Journal of Business Logistics, Vol. 10 No. 2, pp. 73-89, available at: http://search. ebscohost.com/login. aspx $?$ direct $=$ true $\& \mathrm{db}=$ bth $\& A N=5119011 \&$ site $=$ ehost-live\&scope $=$ site . 
Breen, L. and Xie, Y. (2015), "Waste not, want not-what are the drivers of sustainable medicines recycling in national health service hospital pharmacies (UK)? [article]", International Journal of Procurement Management, Vol. 8 Nos 1-2, pp. 82-103, doi: 10.1504/IJPM.2015.066289.

Childerhouse, P. and Towill, D.R. (2003), "Simplified material flow holds the key to supply chain integration”, Omega, Vol. 31 No. 1, pp. 17-27, doi: 10.1016/S0305-0483(02)00062-2.

Christopher, M. (2005), Logistics and Supply Chain Management: Strategies for Reducing Costs, Improving Services and Managing the Chain of Demand, 3rd ed., Financial Times Prentice Hall, New York, NY.

Christopher, M. and Lee, H. (2004), "Mitigating supply chain risk through improved confidence", International Journal of Physical Distribution and Logistics Management, Vol. 34 No. 5, pp. 388-396, doi: 10.1108/09600030410545436.

Davis, T. (1993), "Effective supply chain management”, Sloan Management Review, Vol. 34 No. 4, pp. 35-46.

Dev, N.K., Shankar, R. and Swami, S. (2020), "Diffusion of green products in industry 4.0: reverse logistics issues during design of inventory and production planning system", International Journal of Production Economics, Vol. 223, 107519, doi: 10.1016/j.ijpe.2019.107519.

Eltayeb, T.K., Zailani, S. and Ramayah, T. (2011), "Green supply chain initiatives among certified companies in Malaysia and environmental sustainability: investigating the outcomes", Resources, Conservation and Recycling, Vol. 55 No. 5, pp. 495-506, doi: 10.1016/j.resconrec.2010.09.003.

Flynn, B.B., Koufteros, X. and Lu, G. (2016), "On theory in supply chain uncertainty and its implications for supply chain integration”, Journal of Supply Chain Management, Vol. 52 No. 3, pp. 3-27, doi: 10.1111/jscm.12106.

Franco, M.A. (2017), "Circular economy at the micro level: a dynamic view of incumbents' struggles and challenges in the textile industry [article]", Journal of Cleaner Production, Vol. 168, pp. 833-845, doi: 10.1016/j.jclepro.2017.09.056.

Geissdoerfer, M., Morioka, S.N., de Carvalho, M.M. and Evans, S. (2018), "Business models and supply chains for the circular economy [article]", Journal of Cleaner Production, Vol. 190, pp. 712-721, doi: 10.1016/j.jclepro.2018.04.159.

Govindan, K. and Bouzon, M. (2018), "From a literature review to a multi-perspective framework for reverse logistics barriers and drivers [review]", Journal of Cleaner Production, Vol. 187, pp. 318-337, doi: 10.1016/j.jclepro.2018.03.040.

Govindan, K., Palaniappan, M., Zhu, Q. and Kannan, D. (2012), “Analysis of third party reverse logistics provider using interpretive structural modeling", International Journal of Production Economics, Vol. 140 No. 1, pp. 204-211, doi: 10.1016/j.ijpe.2012.01.043.

Govindan, K., Soleimani, H. and Kannan, D. (2015), "Reverse logistics and closed-loop supply chain: a comprehensive review to explore the future", European Journal of Operational Research, Vol. 240 No. 3, pp. 603-626, doi: 10.1016/j.ejor.2014.07.012.

Guo, S., Shen, B., Choi, T.M. and Jung, S. (2017), "A review on supply chain contracts in reverse logistics: supply chain structures and channel leaderships [article]", Journal of Cleaner Production, Vol. 144, pp. 387-402, doi: 10.1016/j.jclepro.2016.12.112.

Hayrutdinov, S., Saeed, M.S.R. and Rajapov, A. (2020), "Coordination of supply chain under blockchain system-based product lifecycle information sharing effort [article]", Journal of Advanced Transportation, Vol. 2020, 5635404, doi: 10.1155/2020/5635404.

Hazen, B.T., Huscroft, J., Hall, D.J., Weigel, F.K. and Hanna, J.B. (2014), "Reverse logistics information system success and the effect of motivation [article]", International Journal of Physical Distribution and Logistics Management, Vol. 44 No. 3, pp. 201-220, doi: 10.1108/IJPDLM-112012-0329.

Hervani, A.A., Helms, M.M. and Sarkis, J. (2005), "Performance measurement for green supply chain management”, Benchmarking: An International Journal, Vol. 12 No. 4, pp. 330-353, doi: 10.1108/ 14635770510609015. 
MSCRA

3,1

Kagermann, H., Helbig, J., Hellinger, A. and Wahlster, W. (2013), Recommendations for Implementing the Strategic Initiative Industrie 4.0: Securing the Future of German Manufacturing Industry; Final Report of the Industrie 4.0 Working Group, Forschungsunion, Frankfurt.

Khor, K.S., Udin, Z.M., Ramayah, T. and Hazen, B.T. (2016), "Reverse logistics in Malaysia: the contingent role of institutional pressure", International Journal of Production Economics, Vol. 175, pp. 96-108, doi: 10.1016/j.ijpe.2016.01.020.

Knight, F.H. (1921), Risk, Uncertainty and Profit, Houghton Mifflin Company, Boston.

Kumar, S., Teichman, S. and Timpernagel, T. (2012), "A green supply chain is a requirement for profitability [review]", International Journal of Production Research, Vol. 50 No. 5, pp. 1278-1296, doi: 10.1080/00207543.2011.571924.

Larson, P.D. and Gammelgaard, B. (2001), "The logistics triad: survey and case study results", Transportation Journal, Vol. 41 Nos 2/3, pp. 71-82, available at: http://www.jstor.org/stable/ 20713494.

Lee, V.H., Ooi, K.B., Chong, A.Y.L. and Sohal, A. (2018), "The effects of supply chain management on technological innovation: the mediating role of guanxi [article]", International Journal of Production Economics, Vol. 205, pp. 15-29, doi: 10.1016/j.ijpe.2018.08.025.

Mason-Jones, R. and Towill, D.R. (1998), "Shrinking the supply chain uncertainty circle", IOM Control, Vol. 24 No. 7 , pp. 17-22.

Miller, K.D. (1992), “A framework for integrated risk management in international business”, Journal of International Business Studies, Vol. 23 No. 2, pp. 311-331.

Morgan Tyler, R., RicheyRobert, G. Jr and Autry Chad, W. (2016), "Developing a reverse logistics competency: the influence of collaboration and information technology", International Journal of Physical Distribution and Logistics Management, Vol. 46 No. 3, pp. 293-315, doi: 10.1108/ IJPDLM-05-2014-0124.

Prater, E. (2005), "A framework for understanding the interaction of uncertainty and information systems on supply chains", International Journal of Physical Distribution and Logistics Management, Vol. 35 No. 7, pp. 524-539, doi: 10.1108/09600030510615833.

Richey, R.G., Stefan, E.G. and Patricia, J.D. (2005), “The role of resource commitment and innovation in reverse logistics performance", International Journal of Physical Distribution and Logistics Management, Vol. 35 No. 4, pp. 233-257, doi: 10.1108/09600030510599913.

Rovira, C., Guerrero, S. and Lopezosa (2019), "Ranking by relevance and citation counts, a comparative study: google scholar, microsoft academic, WoS and Scopus", Future Internet, Vol. 11 No. 9, p. 202, doi: 10.3390/fi11090202.

Rubio, S., Chamorro, A. and Miranda, F.J. (2008), "Characteristics of the research on reverse logistics (1995-2005) [article]", International Journal of Production Research, Vol. 46 No. 4, pp. 1099-1120, doi: $10.1080 / 00207540600943977$.

Sanchez-Rodrigues, V., Stantchev, D., Potter, A., Naim, M. and Whiteing, A. (2008), "Establishing a transport operation focused uncertainty model for the supply chain”, International Journal of Physical Distribution and Logistics Management, Vol. 38 No. 5, pp. 388-411, doi: 10.1108/ 09600030810882807.

Sanchez-Rodrigues, V., Potter, A. and Naim, M.M. (2009), "The impact of logistics uncertainty on sustainable transport operations", International Journal of Physical Distribution and Logistics Management, Vol. 40 Nos 1-2, pp. 61-83, doi: 10.1108/09600031011018046.

Sanchez-Rodrigues, V., Potter, A. and Naim, M.M. (2010), "Evaluating the causes of uncertainty in logistics operations", International Journal of Logistics Management, Vol. 21 No. 1, pp. 45-64.

Simangunsong, E., Hendry, L.C. and Stevenson, M. (2012), "Supply-chain uncertainty: a review and theoretical foundation for future research", International Journal of Production Research, Vol. 50 No. 16, pp. 4493-4523, doi: 10.1080/00207543.2011.613864.

Slone, R.E., Mentzer, J.T. and Paul Dittmann, J. (2007), "Are you the weakest link in your company's supply chain? [review]", Harvard Business Review, Vol. 85 No. 9, pp. 116-127+150, available at: 
https://www.scopus.com/inward/record.uri?eid=2-s2.0-34548621084\&partnerID=40\&md5=a854 55ff475e958935210148a9ab8708.

Sreedevi, R. and Saranga, H. (2017), "Uncertainty and supply chain risk: the moderating role of supply chain flexibility in risk mitigation", International Journal of Production Economics, Vol. 193, pp. 332-342, doi: 10.1016/j.jpe.2017.07.024.

Sundarakani, B., de Souza, R., Goh, M., Wagner, S.M. and Manikandan, S. (2010), "Modeling carbon footprints across the supply chain", International Journal of Production Economics, Vol. 128 No. 1, pp. 43-50, doi: 10.1016/j.jpe.2010.01.018.

Turrisi, M., Bruccoleri, M. and Cannella, S. (2013), "Impact of reverse logistics on supply chain performance [article]", International Journal of Physical Distribution and Logistics Management, Vol. 43 No. 7, pp. 564-585, doi: 10.1108/IJPDLM-04-2012-0132.

Wang, M. (2011), Reverse Logistics Optimization, Massey University, Palmerston North.

Wang, M. (2016), Logistics Capability, Supply Chain Uncertainty and Risk, and Logistics Performance: An Empirical Analysis of the Australian, Courier Industry RMIT University, Melbourne.

Wang, M. (2018), "Impacts of supply chain uncertainty and risk on the logistics performance", Asia Pacific Journal of Marketing and Logistics, Vol. 30 No. 3, pp. 689-704, doi: 10.1108/APJML-042017-0065.

Wang, M. and Jie, F. (2019), "Managing supply chain uncertainty and risk in the pharmaceutical industry”, Health Services Management Research, Vol. 33 No. 3, doi: 10.1177/0951484819845305.

Wang, M., Jie, F. and Abareshi, A. (2014), "The measurement model of supply chain uncertainty and risk in the Australian courier industry", Operations and Supply Chain Management: An International Journal, Vol. 7 No. 3, pp. 89-96.

Wang, M., Jie, F. and Abareshi, A. (2015), "Evaluating logistics capability for mitigation of supply chain uncertainty and risk in the Australian courier firms", Asia Pacific Journal of Marketing and Logistics, Vol. 27 No. 3, pp. 486-498, doi: doi:10.1108/APJML-11-2014-0157.

Wang, J.J., Chen, H., Rogers, D.S., Ellram, L.M. and Grawe, S.J. (2017), "A bibliometric analysis of reverse logistics research (1992-2015) and opportunities for future research [review]", International Journal of Physical Distribution and Logistics Management, Vol. 47 No. 8, pp. 666-687, doi: 10.1108/IJPDLM-10-2016-0299.

Wang, M., Wu, Y., Chen, B. and Evans, M. (2021), "Blockchain and supply chain management: a new paradigm for supply chain integration and collaboration", Operations and Supply Chain Management: An International Journal, Vol. 14 No. 1.

Waters, D. (2011), Supply Chain Risk Management Vulnerability and Resilience in Logistics, 2nd ed., Kogan Page, London.

Wilding, R. (1998), "The supply chain complexity triangle: uncertainty generation in the supply chain", International Journal of Physical Distribution and Logistics Management, Vol. 28 No. 8, pp. 599-616, doi: 10.1108/09600039810247524.

\section{Corresponding author}

Michael Wang can be contacted at: michaelwangaus@gmail.com and michael.wang@hct.ac.ae

For instructions on how to order reprints of this article, please visit our website:

www.emeraldgrouppublishing.com/licensing/reprints.htm

Or contact us for further details: permissions@emeraldinsight.com 